\title{
Summer Mesoscale circulation in the Mexican Tropical Pacific
}

A. Trasviña (1,3) and E. D. Barton (2)

(1) CICESE Unidad La Paz, Oceanografía Física, Miraflores 334 e/Mulegé y La Paz, Fracc. Perla, La Paz 23050 BCS, México, (2) Instituto de Investigaciones Marinas, CSIC, Vigo, Spain, (3) Sabbatical stay at CSIC, IIM, Vigo, Spain (trasvi@cicese.mx)

\begin{abstract}
The main components of the large-scale circulation of the Eastern Tropical Pacific were identified in the mid $20^{\text {th }}$ century, but the details of the circulation at length scales of $10^{2}$ $\mathrm{km}$ or less, the mesoscale field, are less known particularly during summer. The winter circulation is characterized by large mesoscale eddies generated by intense cross-shore wind pulses. These eddies propagate offshore to provide an important source of mesoscale variability for the Eastern tropical Pacific. The summer circulation has not commanded similar attention, the main reason being that the frequent generation of hurricanes in the area renders 'in situ' observations difficult. Before the experiment presented here, the large-scale summer circulation of the Gulf of Tehuantepec was thought to be dominated by a poleward flow: the Costa Rica Coastal Current. A drifterdeployment experiment carried out in June 2000, supported by satellite altimetry and wind data, was designed to characterize it. We present a detailed comparison between altimetry-estimated geostrophic and 'in situ' currents estimated from drifters. Our results, however, show no evidence of the existence of a poleward coastal flow. During the 10week period of observations we documented a recurrent pattern of circulation within 500 $\mathrm{km}$ of shore, forced by a combination of local winds and the regional-scale flow. Instead of the Costa Rica Coastal Current we found a summer eddy field capable of influencing large areas of the Eastern tropical Pacific. Even in summer the cross isthmus wind jet is capable of inducing eddy formation.
\end{abstract}

Keywords: surface currents; mesoscale eddies; wind; altimetry; geostrophic currents 


\section{Introduction}

The main components of the large-scale circulation of the Eastern Tropical Pacific were identified in the early work of Wyrtki (1965), but the details of the circulation at length scales of $10^{2} \mathrm{~km}$ or less, the mesoscale field, are poorly known particularly during summer. The winter circulation is characterized by large mesoscale eddies generated by intense wind pulses blowing through mountain passes in the Gulf of Tehuantepec, Mexico (Fig. 1) and Papagayo, Nicaragua [Barton et al., 1993; Trasviña et al., 1995; Giese, Carton and Holl, 1994]. These are an important source of mesoscale variability for the eastern tropical Pacific. The summer circulation has not commanded similar attention. This is largely because many hurricanes spin-up off the Gulf of Tehuantepec at this time of year rendering 'in situ' observations difficult.

Winter eddies were observed in December 1973 in AVHRR (advanced very high resolution radiometer) satellite imagery [Stumpf, 1975]. Later, more detailed satellite observations by Stumpf and Legeckis [1977] revealed the signature of a $300 \mathrm{~km}$ diameter eddy, after the occurrence of three successive wind events in February 1976. More recent analyses of GEOSAT altimetry data [Leben et al., 1990], validated by AVHRR imagery, reveal the formation of up to three eddies each winter between 1985 and 1989 in the Gulf of Tehuantepec. These authors report eddy propagation offshore following a west-southwestward track for over 15 degrees of longitude. Hansen and Maul [1991] observed several drifters trapped in warm eddies, migrating westward as far as $115^{\circ} \mathrm{W}$. The large-scale impact of these features is established by Giese, Carton and Holl [1994], who study the variability of sea level using over a year of TOPEX altimetry data for the Eastern Pacific. After removing the annual harmonic, they find a band of mesoscale activity between 10 and $12^{\circ} \mathrm{N}$ extending from the coast to $120^{\circ} \mathrm{W}$. They clearly show this to be produced by 5 offshore propagating eddies formed off the gulfs of Tehuantepec and Papagayo in the period between September 1992 and February 1994. The eddy tracks in the altimetry data suggest that two formed in the Gulf of Tehuantepec and the rest in Papagayo. The Tehuantepec eddies initially traveled southwestward before taking a more westward route, while Papagayo eddies tended to stay at the latitude of formation. One Tehuantepec eddy lasted from December to August and traveled westward to $130^{\circ} \mathrm{W}$ (see Giese, Carton and Holl, 1994, their figure 8). Drifter observations by Trasviña et al. [2003] also indicate an initial southwestward propagation off Tehuantepec, ascribed to asymmetries in the distribution of the mass, and therefore vorticity, field within the eddy. 
The offshore sea-level signature of these eddies disappears in the summer, coinciding with the strengthening of the North Equatorial Countercurrent. Recently, Palacios and Bograd (2005) analyze 12 years of altimetry data for the region. Although they do not make a distinction between winter and summer circulation, they report that, on average, the eddy season begins in late October and lasts approximately 250 days until early July. These authors report a mean of 3.5 Tehuantepec and 2.2 Papagayo eddies formed each year. Zamudio et al. (2006) report interannual variability of eddy generation in the Gulf of Tehuantepec during successive cold seasons (October-April) between 1992 and 2000 on the basis of sea level anomalies from Topex/Poseidon altimetry. Three to five eddies are formed off the Gulf of Tehuantepec each season between 1992 and 1996. In contrast, during the 1997-1998 El Niño event at least seven eddies are formed. During the ensuing la Niña event, which affected the cold seasons of 1998 and 1992, only two and three eddies were formed, respectively. These authors also suggest that Tehuantepec eddies can be generated during seasons of low wind conditions by freely propagating baroclinic coastally trapped waves capable of triggering baroclinic instabilities.

The large-scale summer circulation of the Gulf of Tehuantepec was described by Wyrtki (1965) on the basis of ship drift records as being dominated by the poleward flow of the Costa Rica Coastal Current extending as far north as Cabo Corrientes $\left(20^{\circ} \mathrm{N}\right)$. We present results from a drifter deployment experiment in June, 2000 supported by satellite wind (QuickScat) and multi-satellite altimetry grids from the Enhanced Ocean Data Assimilation and Climate Prediction project (ENACT). This experiment was designed to study such flow but, as reported below, no evidence of its existence was found. Instead, this work demonstrates the presence of a summer eddy field capable of influencing large areas of the Eastern tropical Pacific. The large scale field is described using the altimetry grids from ENACT.

\section{Methods}

All floats deployed in this experiment were standard surface drifters of the TOGA-WOCE (Tropical Ocean and Global Atmosphere-World Ocean Circulation Experiment) surface velocity program (SVP) as described by Lumpkin and Pazos (2006). They are drogued with a holey sock centered at $15 \mathrm{~m}$ depth and include a surface float with batteries and a transmitting platform. These drifters are designed to follow the water to within $\pm .013 \mathrm{~ms}^{-1}$ in $10 \mathrm{~ms}^{-1}$ winds [Niiler et al., 1995]. This platform enables Service Argos' satellites to 
obtain fixes of their position several times every day. Position data were acquired and processed by the Drifting Buoy Data Assembly Center (DAC, Atlantic Oceanographic Marine Laboratory) following procedures described by Hansen and Poulain (1996). The final products were the six-hourly interpolated position time series used here.

The drifter experiment was designed to gather detailed observations of the Costa Rica Coastal Current reported by Wyrtki (1965). The deployment was planned for the most intense phase reported by this author (early summer) and the place chosen for the experiment was the Gulf of Tehuantepec $\left(15^{\circ} \mathrm{N}\right)$. All 30 drifters were deployed at the grid points shown in figure 1 from a ship of opportunity based in the Port of Salina Cruz. Maps of geostrophic currents were estimated from altimetry data following the method of Strub and James (2002). We used gridded maps of sea level anomalies from the European Union's ENACT Program (Enhanced ocean data assimilation and climate prediction, http://www.cls.fr/enact). These maps were produced using data from several altimetry missions. As will be shown, they resolve with great accuracy most of the mesoscale features discussed in this work. The long-term mean climatology was that of Levitus and Gelfeld (1992). From this we obtained mean dynamic heights relative to $1000 \mathrm{~m}$ that were later added to the anomalies in order to compute geostrophic currents. The maps represent weekly averages and resolve the current field in a horizontal grid of $1 / 3$ of a degree.

Winds from the SeaWinds Scatterometer on QUICKSCAT are used to produce the high resolution wind field maps shown here. The level 3 data set is provided by the Physical Oceanography Distributed Active Archive Center (PO-DAAC) on a grid with a horizontal resolution of $0.25^{\circ}$, equivalent to about 25 km (ftp://podaac.jpl.nasa.gov/pub/ocean wind/quikscat/L3/).

\section{Results}

\section{Coastal circulation}

Figure 2 shows current fields from 6-hourly interpolated drifter data obtained during the field experiment. Each map was constructed using 14 days of data to describe four periods in the evolution of the current field over almost two months. For instance, current vectors for the initial period between 24 June and 7 July are shown for those drifters inside the eddy field (Figure 2a) and outside it (Figure 2e). The circulation in the gulf was dominated by a large dipolar structure centered on $95^{\circ} \mathrm{W}$ with 16 of the 30 original drifters tracking this flow pattern (Fig 2a). The remaining 13 drifters (one failed) were left 
outside the eddies and describe a disordered flow pattern (Fig 2e). With few exceptions the more coastal tracks progressed in mostly eastward directions (dark current vectors). One drifter west of the Gulf advanced towards the northwest along the coast and another one moved progressively offshore during the period (both drawn with light current vectors because of their westward components).

Current vectors from 8 to 21 July inside (Figure $2 b$ ) and outside (Figure 2f) the eddies reveal that most drifters originally inside the cyclone had now been incorporated into the anticyclone. Of the drifters remaining outside the eddy on 8 July, two nearby drifters were quickly incorporated into it and only three remained far from the eddy (Figure 2f) in this period. Two exhibited slow and erratic behavior south of $14^{\circ} \mathrm{N}$. The one found farther south was a new arrival from outside the area not deployed in the present study. The only drifter close to shore initially progressed slowly towards the coast and then advanced northwestward until it ran aground. The drifter found further west followed a slow irregular anticyclonic quasi-circular path of period around $20 \mathrm{~d}$. It performed a small rapid cyclonic loop where it interacted with the southern edge of the principal anticyclone. Meanwhile the drifters inside the eddy (Fig 2b) described a growing, coherent structure with a diameter of some $250 \mathrm{~km}$ spanning from $95^{\circ}$ to almost $98^{\circ} \mathrm{W}$. Current vectors inside the eddy had an average magnitude of about $0.5 \mathrm{~m} \mathrm{~s}^{-1}$. The eddy had also propagated offshore, its center moving southwest of the previous position. Regarding the fate of the cyclone, it was probably spinning down while gradually expelling drifters. These became immediately trapped in the energetic circulation of the anticyclone or, in one, case ran aground. The transfer of drifters between eddies can be interpreted in terms of the work of Shapiro et al. (1997), who found that a lagrangian drifter will remain inside an eddy while positioned within its 'trap zone'. This is defined for the steady state as the area bounded by the last closed streamline or 'separatrix' inside of which every streamline is closed. The trap zone can expand or contract as the ratio of the eddy to the background velocity varies in time. Therefore, when an eddy moves into significant/negligible horizontal shear its trap zone will shrink/grow.

From 22 July to 4 August (Figures $2 \mathrm{c}$ and $2 \mathrm{~g}$ ) the anticyclonic eddy continued to dominate the circulation. The flow within it appeared well organized, its shape was nearly circular and its center had moved farther offshore in the same southwestward direction as before. The two remaining drifters in the far field exhibited contrasting behaviors. The one found farther to the west and belonging to the original set showed no net motion while following a slow clockwise circular path. The other drifter followed a roughly 
rectilinear path towards the northeast, until close to shore it turned northwestward in a poleward flow.

Finally, from 5 to 18 August (Figures $2 \mathrm{~d}$ and $2 \mathrm{~h}$ ) the eddy remained coherent and well organized. Its center had continued to propagate offshore to the southwest. In 56 days the eddy centre, originally located at about $15.5^{\circ} \mathrm{N}, 95.5^{\circ} \mathrm{W}$, had moved to approximately $14.5^{\circ} \mathrm{N}, 97.2^{\circ} \mathrm{W}$. This translation of some $200 \mathrm{~km}$ in 56 days represents a mean propagation speed of $3.5 \mathrm{~km} \mathrm{~d}^{-1}$. Of the two drifters moving in the far-field, one was advancing westward north of $13^{\circ} \mathrm{N}$, while the other had reversed its alongshore poleward track of the previous period. The latter was now progressing, slowly and erratically, southeastward along the coast, exactly the opposite of what would be expected in a poleward flow such as the Costa Rica Coastal Current.

\section{The wind and the eddy field}

Our observational sequence begins on June 19 when Tropical Storm Carlotta was stationed off the gulf at about $13^{\circ} \mathrm{N}, 95^{\circ} \mathrm{W}$. By June 20 it had moved away to about $14.5^{\circ}$ $\mathrm{N}, 99.5^{\circ} \mathrm{W}$ and gained hurricane strength. The presence of a storm significantly alters the large-scale wind flow patterns over the gulf. It is well known to the population of the Port of Salina Cruz (at the head of the gulf) that conditions return to normal after a hurricane only when the winds begins to blow from land (southward). This drifterdeployment experiment begins during one such period after the passage of Carlotta. It provided us with 8 weeks of detailed observations of the coastal circulation unaltered by storm winds. The next hurricane occurred on 5 August, far to the northwest of the gulf (Gilma) and started as a tropical depression at $15^{\circ} \mathrm{N}, 105^{\circ} \mathrm{W}$. Consequently, our observations describe the coastal circulation resulting from local wind forcing, modulated by the background flow discussed later. We observed a complete cycle from the onset of the offshore forcing, to the generation of a transient dipolar structure and later to the survival of an anticyclone that slowly propagates offshore.

The generation of the eddy is clear evidence of the influence of local wind forcing on the circulation of the upper ocean, as shown next. The wind field described by Fig 3 represents a 10-day average from QuikSCAT data. The wind resembles a veering fan with its narrow source at the head of the gulf. The response of the currents to this southward jet is also shown superimposed on the figure. Drifter velocities and trajectories describe a dipolar circulation below the wind funnel: anticyclonic/cyclonic to the right/left of the wind, looking downwind. The structure closely resembles the results of the Crepon \& Richez (1982) analytical solution for the linear Ekman theory in a coastal 
ocean, forced by an offshore wind perpendicular to the coast. Their results include the generation of upwelling/downweling leftright of the wind looking downwind and, associated with this, a dipolar structure in the circulation of the upper layer. Evidence consistent with this type of coastal circulation has been previously reported by Trasviña et al. (2003) off the western coast of Baja California, as a response to offshore 'Santa Ana' wind jets. Also, Chavanne et al. (2002) describe wind jets in the gaps between the Hawaiian Islands and its effect on sea surface temperature and sea level. The evidence presented here are the first direct observations of the circulation pattern found in Crepon \& Richez's analytical result. Note that the nonlinear case was solved by McCreary et al (1989). They showed that the response of a coastal ocean forced by an offshore wind can also be asymmetrical. It consists of an anticyclone and a much weaker cyclone that dissipates after the wind event instead of the dipolar flow of the linear solution. The nonlinear response is observed in the Gulf of Tehuantepec in winter, when the acceleration of the wind jet is more violent and is capable of producing intense advection in the upper ocean. This in turn results in the generation of an asymmetric response: a single anticyclonic eddy (Barton et al, 1993; Trasvina et al., 1995).

Even in the linear case described here the dipolar structure is short-lived. After a few weeks only the anticyclone remains. This is because local conditions do not promote the survival of the cyclonic circulation. In the vicinity of the Gulf of Tehuantepec the thermocline is extremely shallow (sometimes $20 \mathrm{~m}$ ). Clearly, 'doming' of the thermocline would occur in order for intensification of the cyclonic circulation to take place. This would expose the thermocline to surface processes and the eddy could not remain intact. Under these conditions a cyclone is likely to spin-down or perhaps to break into smaller eddies and to eventually dissipate.

A 3-month time series of the N-S wind component is presented in figure 4. This was obtained from daily-averaged QuikSCAT wind data, further area-averaged on a $1^{\circ}$ square in the center of the gulf (shown in the inset). The thick line in figure 4 is the dailyaveraged data and the thin line represents the low-pass signal obtained by applying a 7day filter. The latter reveals two acceleration periods separated by 6 weeks of steadier southward winds. The first acceleration occurs between June 18 and 30, during the deployment of the drifters (Fig 4a), immediately after the offshore passage of hurricane Carlotta. The dipolar structure was formed during these two weeks when the lowfrequency signal gradually increased from near zero values to about $5 \mathrm{~m} \mathrm{~s}^{-1}$ and peak daily-averaged values reached $7 \mathrm{~m} \mathrm{~s}^{-1}$ (thin line). The six following weeks found the 
drifters following near-circular paths inside the eddy while slowly propagating offshore (figures $4 b, 4 c \& 4 d$ ). The second acceleration period commenced in the second week of August and lasted for about 12 days (thick line). The daily means (thin line) reveal that this period ccontained two separate events: the first accelerated from 0 to $15 \mathrm{~m} \mathrm{~s}^{-1}$ in about 5 days and the second from 7 to over $20 \mathrm{~m} \mathrm{~s}^{-1}$ in six days. This was the strongest event of the summer and it was comparable in intensity to a winter event although accelerations were weaker. For comparison, during winter a similar speed increase can take place in less than one day (Brown et al., 1992). At the beginning of this second period the center of the eddy had already moved to about $14.5^{\circ} \mathrm{N}, 97.2^{\circ} \mathrm{W}$, some 300 $\mathrm{km}$ away from its initial position (Fig 4d). This strong event appears to influence the behavior of the eddy in spite of the distance separating it from shore. This was reflected during the following 14 days in the paths of the drifters tracking the eddy (Fig 4e) and is discussed in more detail later. Its offshore motion increased while at the same time the trajectories in its interior became more disorganized than before.

\section{Some eddy dynamics.}

The internal dynamics of the eddies shed light on its generation mechanisms. The ratio of the relative to the planetary vorticity can be regarded as an estimate of the Rossby number of the flow. We estimated this by first smoothing the velocity components using a low-pass filter with a cutoff frequency of $(1 / 42) h^{-1}$. The irregularly distributed data were then linearly interpolated to a regular square grid of $0.1^{\circ}$ in order to compute the derivatives needed to estimate the relative vorticity $(\delta v / \delta x-\delta u / \delta y)$. Before plotting, the data was scaled by the mean planetary vorticity $(f=2 \Omega \sin \varphi$, where $\varphi$ is the mean latitude of the eddy and $\Omega$ the Earth's angular speed). Anticlockwise rotation represents negative vorticity.

Figure $5 a$ shows the field of vorticity ratio for the dipole in the first week of July (see also $2 a$ and $4 a$ ). Similarly large values of the vorticity ratio occur for both the cyclone and the anticyclone. Regions near the center of the cyclone showed vorticity ratios of 0.6 and larger while the anticyclone showed many regions with absolute values between 0.4 and 0.6. This would be an indication of the importance of both linear (pressure gradient terms) and nonlinear (advective terms) processes in the generation of the dipolar structure.

By the second week of August (Fig 5b) only the anticyclone remained. The vorticity ratios were dominated by absolute values from 0.2 to 0.4 , consistent with the predominance of a linear balance of forces. This period occurred towards the end of the 
steady wind period and also within the 6-week steady period of the eddy, as described by the drifter motion (Fig 4c). At this time the eddy was closer to geostrophic balance than at any moment since its formation.

Estimates of azimuthal velocity $\left(C_{\theta}\right)$ follow the formulation used by Simpson et al (1984), based on the horizontal equations of motion in cylindrical coordinates $(r, \theta, z)$. They are obtained by rotation of the Cartesian components to their radial and tangential equivalents, using as rotation angle the phase of each vector.

$$
C_{\theta}=r \delta \theta / \delta t, \quad C_{r}=\delta r / \delta t, \quad w=w
$$

These calculations are intended to show how closely the eddy conforms to solid body rotation during the first 8 weeks of its lifetime. Estimates of gradient speed presented here are also made following the formulation in Simpson et al (1984). Gradient speed includes the centrifugal force, pressure gradient and Coriolis terms in the dynamic balance. Every dot in figure 6 represents an estimate of azimuthal speed at different radial distances, negative for an anticyclonic eddy. The center was estimated simply as the average of all drifter positions within the eddy. The normalized radial coordinate $\left(R / R_{\max }\right)$ varies between the center $(0)$ and the maximum normalized radius (1) tracked by drifters. The thick straight line represents the expected behavior of the azimuthal speed for an eddy in solid-body rotation. Radial components were significantly weaker in general and arose mostly from the translation of the eddy (not shown). This justifies the quasi-lagrangian approach of the following discussion.

Figure 6a corresponds to the eddy at the beginning of the 'steady' phase of the wind (see also Fig 4b). Fewer measurements are available this period because we omitted drifters that spent part of the time outside the eddy. Azimuthal speeds from the center to about 0.3 of the maximum radius loosely conform to the solid-body rotation model. However, there are few observations near the central core and there is a bias towards faster than solid-body rotation speeds outside it. The outer ring (from 0.3 to 1 diameter) shows a wide dispersion of values. This is a consequence of the offshore motion of the eddy and of its interaction with the surrounding fluid. This is the only period when radial (not shown) and azimuthal speeds were comparable in magnitude.

In the next period (Fig 6b) the azimuthal speed profile was better defined. At that time the eddy was closest to geostrophic balance (Fig 5b) and mean N-S wind speeds were weak (top panel in Fig 4 and Fig 4c). The profile of azimuthal speed for this eddy does not appear to conform to a simple model. These observations suggest that only in a small core of perhaps $10 \%$ of the diameter the azimuthal speed profile may conform to 
the solid-body rotation model. Azimuthal speeds then increase nonlinearly outward with the radial coordinate from 0.1 to $0.6 \mathrm{R} / \mathrm{R}_{\max }$. Finally there is a broad outer ring (from 0.6 to $1 \mathrm{R} / \mathrm{R}_{\max }$ ) that shows a wide dispersion of values where the eddy interacts with the surrounding fluid.

During the next period (Fig 6c) drifter trajectories within the eddy were less regular (Fig 4d). At the same time mean N-S wind speeds reached their weakest magnitudes in the observation period (top panel in Fig 4). Azimuthal speeds in figure 6c show a wider dispersion of values throughout the eddy. There is now a central region from the center to about $0.6 \mathrm{R} / \mathrm{R}_{\max }$ where the radial profile is loosely linear. The outer ring where the eddy interacts with the surrounding fluid remains large. It is about the same size as in the previous period, from 0.6 to $1 \mathrm{R} / \mathrm{R}_{\max }$. Observed azimuthal speeds were no longer faster than the solid-body rotation model (the straight line). In the central region of the eddy the straight line now divides the cloud of azimuthal speeds along the center line. Speeds in the outer ring were also slower than before showing a significant azimuthal speed decrease throughout the eddy. At the same time the drifters describe a small but significant offshore propagation (see figure $4 d$ ). This is responsible for the increase in the range of azimuthal speeds found in the periphery of this eddy, while remaining weaker than the solid-body rotation model.

Finally, figure $6 \mathrm{~d}$ shows the azimuthal velocity field when the eddy appears to be pushed offshore by coastal wind events. The offshore motion is also clearly described by the drifter tracks in Fig 4e. Azimuthal velocity profiles along the radius of the eddy were distorted by the translation and a wide dispersion of values was observed throughout the eddy. In the outer ring (from 0.6 to $1 \mathrm{R} / \mathrm{R}_{\max }$ ) azimuthal speeds increased significantly from the previous period (Fig 6c). Here most azimuthal speed values are now faster than the solid-body rotation model.

\section{The background flow}

Our discussion so far has omitted any reference to the large-scale flow and its influence on the eddy field. This is now done by examining maps of geostrophic currents estimated from multi-satellite altimetry grids of the ENACT program. We follow the method described by Strub and James (2002) to produce weekly maps of geostrophic currents. This involves adding the sea level anomalies (SLAs) to a proxy for the Geoid, in this case, the mean dynamic height relative to $1000 \mathrm{~m}$ obtained from hydrographic data. The long-term mean climatology used was that of Levitus and Gelfeld (1992). The maps represent weekly averages and resolve the current field in a horizontal grid of $1 / 3$ 
of a degree (approximately $30 \mathrm{~km}$ at these latitudes). We compare these estimates with the drifter data available for equivalent time periods.

The drifter deployment took place the week centered on June 28 (Fig 7), starting immediately after the first N-S wind pulse illustrated in Figure 4 (period 4a). Figure $7 \mathrm{a}$ shows the geostrophic velocity field and, for reference, all drifter tracks for the same week are shown superimposed. The most conspicuous features in the geostrophic field are two large eddies found offshore. An anticyclone was found to the south of the gulf (centered at $12.25^{\circ} \mathrm{N}, 96.5^{\circ} \mathrm{W}$ ) and a large cyclone dominated the area west of the gulf (centered at $14.25^{\circ} \mathrm{N}, 99^{\circ} \mathrm{W}$ ). The flank of this cyclone reaches the central gulf with speeds between 0.3 to $0.4 \mathrm{~m} \mathrm{~s}^{-1}$. In the eastern gulf (East of $95^{\circ} \mathrm{W}$ ) the geostrophic circulation was anticyclonic and weaker. Figure $7 \mathrm{~b}$ displays velocity vectors measured by the drifters. In contrast, the circulation reported by drifters in coastal areas of the gulf was dominated by the dipolar structure. Only one drifter found far south and off the coast moved quickly offshore following the large scale geostrophic flow. At this stage all the other drifters described the local flow and its motion showed little relation with the background flow. Although it could be argued that discrepancies may result from shortcomings of the altimetry data base, it is also true that drifter cannot be expected to follow geostrophic paths in shallow waters influenced by the wind. Clearly, Ekman theory is more appropriate to describe this situation. The analytical solution to the linear Ekman problem (Crepon \& Richez, 1982) for a coastal ocean forced by a wind jet perpendicular to the coast predicts the formation of a dipole like the one observed here. This implies that local winds were responsible for this coastal circulation pattern.

Figure 8a shows the geostrophic velocity field for the week centered on July 12 (two weeks after figure 7) and, superimposed, all drifter tracks for the period. Wind conditions for the period were steady as described by Figure 4 (period $4 \mathrm{~b}$ ). In the map of geostrophic currents (Fig 8a) the cyclone is no longer present in the drifter tracks. There was a weak cyclonic structure to the southeast of the anticyclone but none of the drifters became trapped inside it. The large anticyclone previously described in the geostrophic background flow continued to propagate offshore so that its core was now found southwest of the gulf at about $12.5^{\circ} \mathrm{N}, 98^{\circ} \mathrm{W}$. Closer to the coast the geostrophic vectors described a smaller anticyclonic eddy with core at $14.75^{\circ} \mathrm{N}, 96.2^{\circ} \mathrm{W}$. Most of the drifter tracks were found within this structure. Velocity vectors from the drifters (Fig 8b) followed closely the shape of the new anticyclone seen in the background geostrophic flow. In the head of the gulf a few of the geostrophic and drifter current vectors showed 
opposite directions. Nevertheless, remarkable agreement existed between the position of the core and the area occupied by the drifters circling the eddy.

Figure 9a shows the geostrophic field for the week centered on July 26 (four weeks after figure 7), as well as all the drifter tracks for the period. Wind conditions remained steady as seen in Figure 4 (period 4c). The map of geostrophic currents (Fig 9a) reveals a welldeveloped anticyclone southwest of the gulf. Drifters and sea level anomalies follow each other closely to describe the new position and shape of the eddy after its propagation offshore. In figure $9 \mathrm{~b}$ the drifter currents describe a circular anticyclone with a symmetric velocity distribution. At this moment the background geostrophic flow near the eddy was weaker than in previous periods. South of the gulf a coherent jet can be seen extending from the coast towards the southwest but it does not alter the flow around the eddy. The position of the core estimated from both data sources also agrees quite well.

Figure 10 shows the geostrophic field for the week centered on August 9 (six weeks after figure 7). All drifter tracks for the period are superimposed. Wind conditions remained fairly steady (see Figure 4, period 4d). This was also the period with weakest mean N-S winds after the eddies were formed. Both the geostrophic and observed currents showed a quasi-circular signature for an anticyclone still stable. As previously discussed, both the vorticity field (Fig $5 b$ ) and the azimuthal speed distribution (Fig 6c) inside this eddy reveal a linear velocity structure with close to $60 \%$ of its diameter in near solid-body rotation. In the geostrophic velocity field (Fig 10a) the southwestward current previously described is now observed closer to the eddy. The intensification of the geostrophic currents in the southwestern quadrant of the eddy is consistent with some degree of current-eddy interaction. The presence of this current is supported by the westward motion of one drifter (not shown clearly in this figure) found south of the eddy. As mentioned above, vectors estimated from drifters (Fig 10b) show a quasi-circular eddy, although the influence of the current is not obvious due perhaps to limited drifter coverage near this flow. It is clear however that the eddy was not isolated but it was immersed in a background flow of significant magnitude.

To check the agreement between geostrophic and observed speeds we choose data from a 10-day period centered on August 8 (Figure 11), when the eddy appeared more regular in shape and when the drifter observations closely followed the altimetric sea level signal. Figure 11 shows the comparison between geostrophic (open circles), gradient (stars) and drifter (dots) azimuthal speeds. In figure 11a we compare radial 
distributions of azimuthal speeds. The velocity profile described by the drifters (dots) is followed closely by the geostrophic speeds (open circles) although the latter clearly underestimate the former by about 0.2 to $0.4 \mathrm{~m} \mathrm{~s}^{-1}$. Inclusion of the centrifugal force in the balance of forces (the gradient speed estimate, shown as stars in Fig 11) reduces the gap only slightly. Figure 11b clearly shows the linear relationship between observed, geostrophic and gradient speeds, as well as the underestimation of the observed values by the altimetry-estimated speeds. In spite of this significant magnitude difference the drifter tracks accurately follow the propagation of the eddy. Such apparent contradiction result from inherent shortcomings of the sea level maps used to calculate these currents. Although sea-level maps (MSLAs) are quite capable of resolving the large eddies found in this experiment, they have problems resolving the sea level slopes around them. This is due to the relatively large spatial separation between satellite tracks and the necessary smoothing of the raw data used to create these maps. For instance, in order to reduce measurement noise and mapping computer time, the sea level anomalies (SLAs) from TOPEX/POSEIDON are filtered and subsampled. In the latitudes of interest (between $10^{\circ}$ and $30^{\circ} \mathrm{N}$ ) the low-pass filter has a cutoff wavelength of $200 \mathrm{~km}$ and only one point in five (roughly every $35 \mathrm{~km}$ ) is used [Ducet et al, 2000]. Data from other altimetry missions are treated in a similar fashion before incorporating them in the regular grids used here. As a consequence, azimuthal speeds inside this eddy are underestimated by the above-mentioned factors. Figure 11 also shows the radial drifter velocity profile following closely the Gaussian curve (continuous line) from the center to approximately $80 \%$ of the radius of the eddy. Only very close to the center are azimuthal speeds expected to conform with solid-body rotation, although these observations do not show any detail there. In the outer region of the eddy (the remaining $20 \%$ of the radius) the azimuthal speeds exhibit higher variability. This is the region that interacts with the surrounding fluid. If we wished to identify the 'separatrix' (the boundary of the trap zone defined by Shapiro et al., 1997) it would have to be positioned between the inner eddy of Gaussian velocity profile and this outer ring. Clearly, drifters located in the outer ring will exhibit a greater tendency to drift away from the eddy.

Figure 12 shows geostrophic currents for the week centered on August 23 (eight weeks after figure 7) and again drifter tracks are shown superimposed. This was immediately after the second acceleration period of the wind (see Fig. 4). The geostrophic currents (Fig 12a) reveal an anticyclonic eddy interacting with a strong westward flow along its southern flank. An inspection of all available weekly current maps during the observation 
period reveal that this flow originated closer to the Central American coast, at about $14^{\circ}$ $\mathrm{N}$ and was fed by variable coastal flows from north and south, along the coast. At least one drifter track confirmed the presence of this westward flow. Inside the gulf the currents revolved around a new dipolar structure generated by the strongest wind pulse of the summer. This structure was more persistent and remained well defined in the geostrophic chart of the following week (not shown here). One drifter followed the central current jet and continued along the outer ring of the new anticyclone until it became trapped in the circulation of the offshore eddy. Inside the offshore eddy the drifters (Fig 12b) covered a region slightly elongated in the East-West direction and the currents in its Southern and Eastern quadrants were more intense than elsewhere. The dispersion of azimuthal speeds found on the outer ring of the eddy (figure $6 \mathrm{~d}$ ) is a consequence of this intensification. Both drifter and geostrophic currents strengthened in approximately the same areas. This is consistent with the alterations resulting from the interaction of the eddy with the background flow. Furthermore, the horizontal scale of direct influence of the wind was defined by the size of the new dipole and, consequently, it seems unlikely that the eddy was forced away by direct action of the wind.

Summarizing, we have shown that a coastal wind event originating at the head of the gulf of Tehuantepec is indirectly capably of altering the internal dynamics of an eddy found some $300 \mathrm{~km}$ to the southwest of the head of the gulf. The translation of the core of the eddy is an integral measure of its response to this interaction. Figure 13 shows 5 successive estimates of the propagation speed of the eddy. Each of the six core positions used is the geometric mean of 11 days of drifter tracks within the eddy (Fig 13a). The fast initial motion (about $7 \mathrm{~km} \mathrm{~d}^{-1}$ ) occurs when the structures evolve from a dipole to a single anticyclone (from 15.4 to $14.4^{\circ} \mathrm{N}$ ). The anticyclone then continues to propagate offshore at about $8 \mathrm{~km} \mathrm{~d}^{-1}$ for the next 11 days before slowing down. During the following 11 days the eddy center slowly moves towards the southwest (between 14.6 and $14.3^{\circ} \mathrm{N}$ ) at an average speed of about $2 \mathrm{~km} \mathrm{~d}^{-1}$ (Julian day 220, August 7). In the last 11-day period the eddy jumps to a new position $\left(13.3^{\circ} \mathrm{N}, 97.8^{\circ} \mathrm{W}\right)$ some 95 kilometers to the southwest of the previous one, at an average speed of $7.5 \mathrm{~km} \mathrm{~d}^{-1}$. Such a large increase in propagation speed (nearly fourfold) cannot be explained by the internal dynamics of the eddy and must therefore be externally forced. 


\section{Discussion and conclusions}

In this experiment we obtained detailed observations of the summer circulation of the Gulf of Tehuantepec in a period free of hurricanes. We show that persistent southward (offshore) wind events also occur during summer and that the initial response is characterized by a transient dipolar circulation inside the gulf, anticyclonic/cyclonic to the right/left of the wind, looking downwind. The cyclonic side lasts only a few weeks but the anticyclone survives and propagates offshore. Our observations clearly indicate that summer wind events, even if considerably weaker than their winter counterpart, are perfectly capable of generating large eddies in the Gulf of Tehuantepec. Although Zamudio et al. (2006) suggests spin up of anticyclones from instabilities of a coastally trapped waves the eddies we observed appeared to be wind-generated.

The size of this dipole is comparable with the area of the gulf. Outside it the coastal circulation is weak. An unexpected result is that our direct observations do not contain evidence of the existence of the poleward flow of the Costa Rica Coastal Current. Furthermore, the geostrophic current field, validated by drifter data, clearly describe the presence of a number of eddies and current jets but none of these resemble the expected behavior of the Costa Rica Coastal Current as described by Wyrtki (1965). This poleward flow it is indeed present in the long-term mean of the ship-drift data base. However, we believe that such a mean does not represent the actual seasonal cycle of the coastal currents because of its contamination by El Niño events capable of producing poleward propagation and advection along this coast. For example, Strub and James (2002b) describe anomalous coastal poleward flows during the 1997-1998 El Niño, from June to September between the Equator and $24^{\circ} \mathrm{N}$.

Regarding the fate of the cyclone, we believe it to have spun down quickly after formation. This can be explained by a combination of two separate processes. For a cyclonic structure to develop in the Gulf of Tehuantepec it is necessary to form a dome in a shallow and strong pycnocline. This 'doming' process is limited by the thickness of the mixed layer. When the center of the dome approaches the surface it exposes the core of the vortex to the same mixing processes that maintain the mixed layer in place. Quantifying this process it is beyond the scope of this work but since mixing in the Gulf of Tehuantepec is induced by the same wind that generates the dipole, it cannot be disregarded as negligible. The anticyclone survives because, in contrast to the cyclone, its growth and intensification is accompanied by the deepening of the pycnocline. Below 
the anticyclone the ocean is deep (typically $4,000 \mathrm{~m}$ ) and there are no boundaries or mixing sources capable of limiting the deepening of the pycnocline.

The offshore propagation speed is an integral quantity of the eddy - it is not possible to modify it without influencing the dynamics of the entire structure - and it is far from constant. When the eddy is still close to shore the direct action of the wind exerts considerable influence on its motion and it propagates fast, at 7 to $8 \mathrm{~km} \mathrm{~d}^{-1}$. This eddy reaches quasi-geostrophic balance after separating from the coastal influence, when it is 6 to 7 weeks old. At this point its westward motion reaches a minimum of about $2 \mathrm{~km} \mathrm{~d}^{-1}$ probably the self-propagation speed, although we lack data of its hydrographic structure to make an accurate estimate. The occurrence of a second, more intense, wind event near the coast forces the eddy offshore at nearly four times its previous speed. This occurs through the generation of a new wind-forced offshore jet in the head of the gulf.

In summary, this 10-week period includes detailed observations of a coastal circulation pattern forced by local winds and modulated by the background flow. We also observed the onset of a second, much larger and more intense, wind event. Once again, the coastal ocean reacted by generating a dipolar circulation structure. This time the structure was large enough to be detected by altimetry measurements and was confirmed by the track of one surface drifter. We believe this to be a recurrent pattern for the summer season of the Gulf of Tehuantepec. 


\section{List of figures}

Figure 1. The gulfs of Tehuantepec and Papagayo. The arrows indicate mountain gaps. The lower inset shows drifter deployment positions.

Figure 2. Currents from 6-hourly interpolated drifter data. Each map includes 14 days of data with westerly vectors drawn in gray. The left column ( $a$ to $d$ ) includes drifters trapped in the eddy field: a) from 24 June to 7 July ; b) from 8 to 21 July; $c$ ) from 22 July to 4 August; $d$ ) from 5 to 18 August. The right column (e, $f, g$ and $h$ ) shows drifters outside eddies for equivalent periods.

Figure 3. Dipolar structure in the coastal currents as a response to an offshore breeze. This result is consistent with the analytical solution of the linear Ekman problem obtained by Crepon \& Richez (1982).

Figure 4. N-S wind component time series. These are daily averaged quickscat data, further area-averaged on the $1^{\circ}$ square centered in $95^{\circ} \mathrm{W} 15^{\circ} \mathrm{W}$ (see inset). The thick line is the low-frequency variability after smoothing with a $1 / 7 \mathrm{~d}^{-1}$ cutoff frequency lowpass filter. The maps below show drifter tracks for the different 14day periods marked with stars, from left to right: a) from 24 June to 7 July ; b) from 8 to 21 July; c) from 22 July to 4 August; d) from 5 to 18 August; e) from 19 August to 1 September.

Figure 5. Contours of vorticity ratio estimated from 6-hourly interpolated drifter data gridded every $0.1^{\circ}$. These are the relative vorticity values scaled by the mean planetary vorticity $(f)$. Before gridding drifter velocity components were individually smoothed using a low pass filter with 1/42 hour ${ }^{-1}$ cutoff frequency. Gray/black lines are used for positive/negative vorticity ratios and the velocity field is drawn in the background. The inset shows the density of float data. Maps are produced using 14 days of data: a) from 24 June to 7 July; b) from 22 July to 4 August.

Figure 6. Azimuthal speeds vs. normalized radius (R/Rmax). The dark line is the solidbody rotation model: a) from 8 to 21 July; b) from 22 July to 4 August; c) from 5 to 18 August d) from 19 August to 1 September.

Figure 7. Comparison between Geostrophic currents estimated from altimetry and observed drifter currents for the week centered on June 28: a) geostrophic vectors (positions of drifter observations in gray dots); b) drifter vectors.

Figure 8. Same as figure 7 for the week centered on July 12: a) geostrophic vectors (positions of drifter observations in gray dots); b) drifter vectors. 
Figure 9. Same as figure 7 for the week centered on July 26: a) geostrophic vectors (positions of drifter observations in gray dots); b) drifter vectors.

Figure 10. Same as figure 7 for the week centered on August 9: a) geostrophic vectors (positions of drifter observations in gray dots); b) drifter vectors.

Figure 11. Radial distribution of azimuthal speeds for a 10-day period of drifter and altimetry measurements between 4 and 13 August, 2000: a) azimuthal speed vs. normalized radius (R/Rmax). Dots mark speeds from drifters, open circles are geostrophic speeds estimated from altimetry and stars represent gradient speed estimates. The broken line is the solid-body rotation model and the solid line is the adjustment of the drifter observations to a Gaussian curve. b) Comparison of radial mean values of azimuthal speeds: geostrophic vs. drifter (open circles) and gradient vs. drifter speed (stars).

Figure 12. Same as figure 7 for the week centered on August 23: a) geostrophic vectors (positions of drifter observations in gray dots); b) drifter vectors.

Figure 13. Offshore propagation from 8 weeks of drifter data: a) Dots mark the position the eddy center estimated from averaging 11 days of drifter positions.

Consecutive numbers indicate the mean position at which propagation speed is estimated b) Propagation speeds in $\mathrm{km} \mathrm{d}^{-1}$. 


\section{References}

Barton, E.D., M.L. Argote, J. Brown, P.M. Kosro, M. Lavin, J.M. Robles, R.L. Smith, A. Trasviña, H.S. Vélez (1993). Supersquirt: Dynamics of The Gulf of Tehuantepec, Mexico, OCEANOGRAPHY, Vol. 6, No. 1, pp. 23-30.

Brown J., E.D. Barton, M. Kosro, R.L. Smith, A. Trasviña and H.S. Vélez (1992). Estimation of Surface winds from Upward Looking Acoustic Doppler Current Profilers Journal of Geophysical Research, OCEANS, Vol. 97, No C11, pp 17925-17930.

Chavanne C., P. Flament, R. Lumpkin, B. Dousset and A. Bentamy (2002). Can. J. Remote Sensing, Vol. 28, No. 3, pp. 466-474.

Crepon, M., Richez, C. (1982). Transient upwelling generated by two-dimensional atmospheric forcing and variability in the coastline. Journal of Physical Oceanography 12, 1437-1456.

Ducet N., P. Y. Le Traon and G. Reverdin (2000). Global high-resolution mapping of ocean circulation from TOPEX/Poseidon and ERS-1 and -2 . Journal of Geophysical Research,105, C8, pp 19,477-19,498

Giese, B., Carton, J. and Holl, L. (1994). Sea level variability in the eastern tropical Pacific as observed by TOPEX and Tropical Ocean--Global Atmosphere Tropical Atmosphere--Ocean Experiment. Journal of Geophysical Research 99(C12): doi: 10.1029/94JC01814. issn: 0148-0227

Hansen, D.V. and P.-Marie Poulain (1996). Quality Control and Interpolations of WOCE/TOGA Drifter Data. J. Atmos. Oceanic Tec., 13, 900-909.

Levitus, S., \& Gelfeld, R. (1992). NODC inventory of physical oceanography profiles. In Key to oceanography records documentation, No. 18. Washington, DC: US Government Printing Office.

Lumpkin, R. and M. Pazos, 2006: Measuring surface currents with Surface Velocity Program drifters: the instrument, its data, and some recent results. Chapter two of Lagrangian Analysis and Prediction of Coastal and Ocean Dynamics (LAPCOD) ed. A. Griffa, A. D. Kirwan, A. J. Mariano, T. Ozgokmen, and T. Rossby.

McCreary, J, H.S. Lee and D.B. Enfield (1989). The response of the coastal ocean to strong offshore winds: with application to the circulation in the Gulf of Tehuantepec and Papagayo. Journal of Marine Research, 47, 1.

Niiler, P. P., A. L. Sybrandy, K. Bi, P. Poulain, and D. Bitterman (1995). Measurements of the water-following capability of holey sock and TRISTAR drifters, Deep Sea Res., 42, 1837-1858.

Palacios D. M., S. J. Bograd (2005), A census of Tehuantepec and Papagayo eddies in the northeastern tropical Pacific, Geophys. Res. Lett., 32, L23606, doi:10.1029/2005GL024324.

Shapiro, G.I., E.D. Barton and S.L. Meschanov (1997). Capture and release of Lagrangian floats by eddies in shear flow. Journal of Geophysical Research, OCEANS, Vol. 102, No. C13, pp.27887-27902.

Simpson, Dickey and Koblinsky (1984). An offshore Eddy in the California Current System. Part I: interior dynamics. Progress in Oceanography, Vol. 13, pp 5-49.

Strub, P.T. and C.James (2002). The 1997-1998 oceanic El Niño signal along the southeast and northeast Pacific boundaries - an altimetric view. Progress in Oceanography 54, 439-458.

Strub, P.T. and C.James (2002b). Altimeter-derived surface circulation in the large-scale NE Pacific Gyres. Part2: 1997-1998 El Niño anomalies. Progress in Oceanography 54, 439-458. 
Trasviña, A., E.D. Barton, J. Brown, H.S. Vélez, M. Kosro and R.L. Smith (1995). Offshore Wind Forcing in the Gulf of Tehuantepec, Mexico: the asymmetric circulation. Journal of Geophysical Research, OCEANS, Vol. 100, No. C10, pp.20649-20663.

A. Trasviña, E.D. Barton, H.S. Velez and J. Brown. Frontal subduction of a cool surface water mass in the Gulf of Tehuantepec (2003). Geofísica Internacional, Vol. 42.1, pp. 101-114, Enero-Marzo.

Zamudio, L., H. E. Hurlburt, E. J. Metzger, S. L. Morey, J. J. O'Brien, C. Tilburg, and J. Zavala-Hidalgo (2006), Interannual variability of Tehuantepec eddies, J. Journal of Geophysical Research, Vol. 111, C05001, doi:10.1029/2005JC003182, 2006

Wyrtki, K., 1965b. Surface currents of the eastern tropical Pacific ocean. Inter-American Tropical Tuna Commission Bulletin, 9, 271-304.

\section{Acknowledgements}

We wish to thank Miguel Angel Cosio and Hugo Herrera from CICESE La Paz (Mexico), Santiago Velez from the Universidad Nacional Metropolitana (Mexico) and the captain and crew of the shrimp boat "Fauna Marina". The global Lagrangian drifters were kindly provided and tracked by the Surface Velocity Program (Scripps Institution of Oceanography, La Jolla), courtesy of Peter Niiler. We wish to recognize the work of Mayra Pazos and the team of the Global Drifter Data Assembly Center (NOAA-AOML http://www.aoml.noaa.gov/phod/dac/dacdata.html). Valuable logistical support was provided by the personnel of the Centro Regional de Investigacion Pesquera of Salina Cruz (Mexico) and we are particularly grateful to Alexandra Gutierrez and Oswaldo Morales. Also, personnel from the Salina Cruz and Huatulco detachments of the Secretaria del Medio Ambiente y Recursos Naturales (Mexico) contributed to the success of the field work. Products from ESA's ERS-1 and ERS-2 data, CNES/NASA TOPEXIPOSEIDON data and CLS "SLA" were used. The altimeter products were produced by the CLS Space Oceanography Division as part of the Environment and Climate EU ENACT project (EVK2-CT2001-00117) and with support from CNES. QuickSCAT level 3 daily data is freely available at the web site of the Jet Propulsion Laboratory: http://podaac.jpl.nasa.gov/products/product109.html. Funding for this project came from the Consejo Nacional de Ciencia y Tecnología (CONACYT, Mexico), project 32500-T. ATC is a grant holder of the Sistema Nacional de Investigadores of CONACYT (Ref 12406). Partial funding was also provided by the Oceanology Division of CICESE and by CICESE Unidad La Paz. This work was written during a sabbatical stay ay the Instituto de Investigaciones Marinas de Vigo (CSIC, Spain), funded by the Ministerio de Educacion y Ciencia (Spain) through the "Programa de ayudas para movilidad de Profesores de Universidad e Investigadores Españoles y Extranjeros" (Ref SAB20040212). 
Click here to download Figure: Figure1.doc

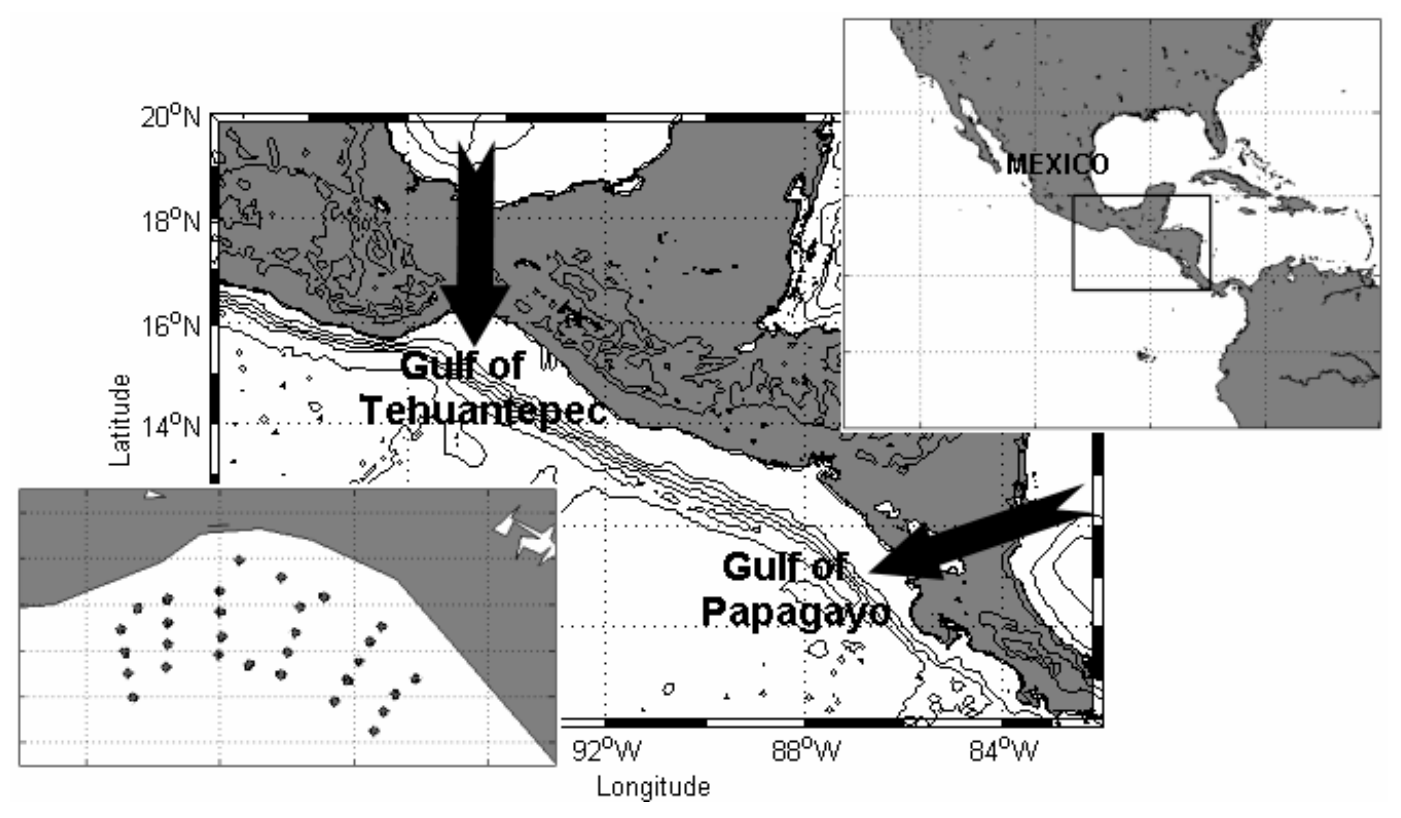


Figure 2
Click here to download Figure: Figure2.doc
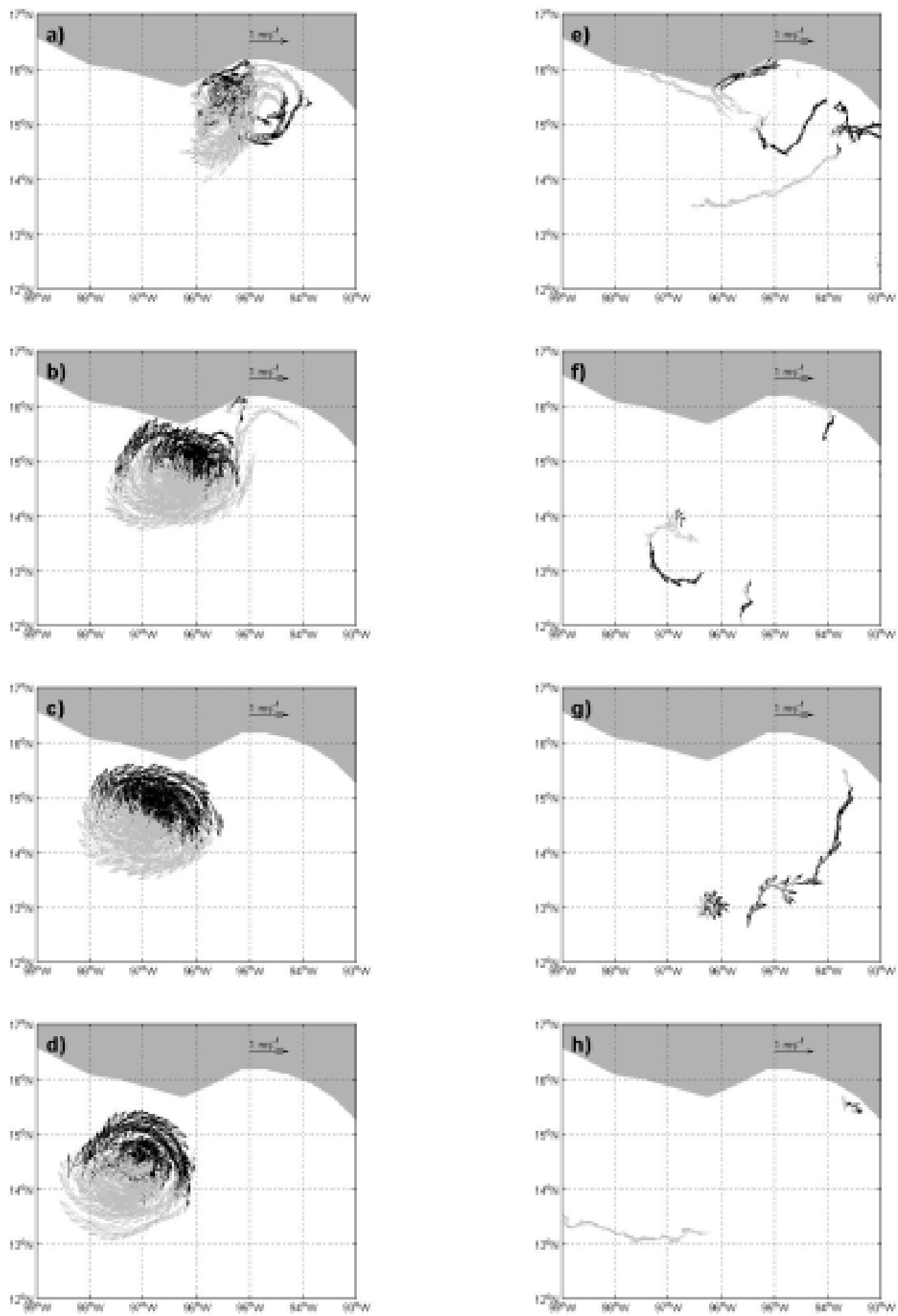






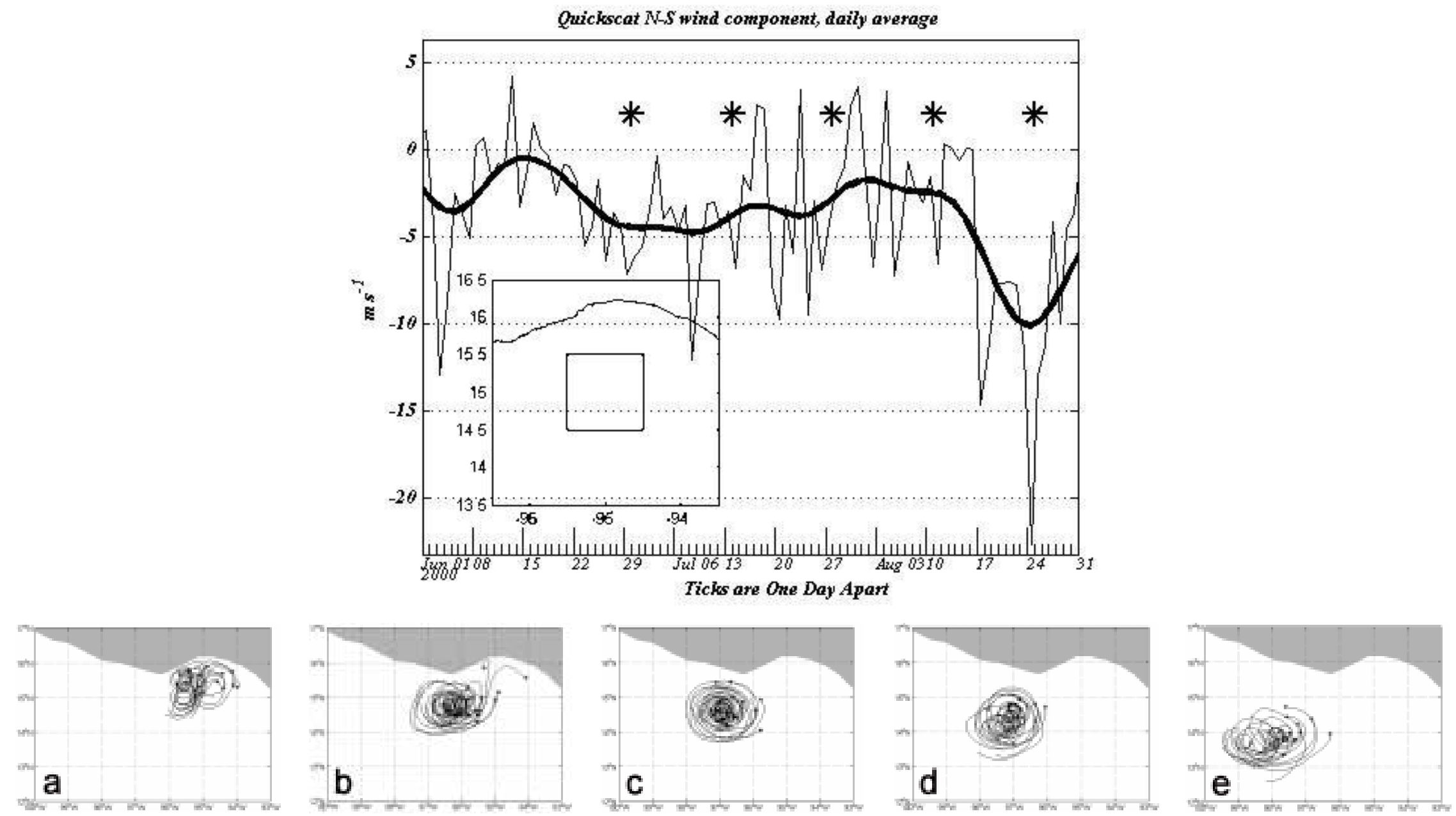
Figure 5
Click here to download Figure: Figure5.doc

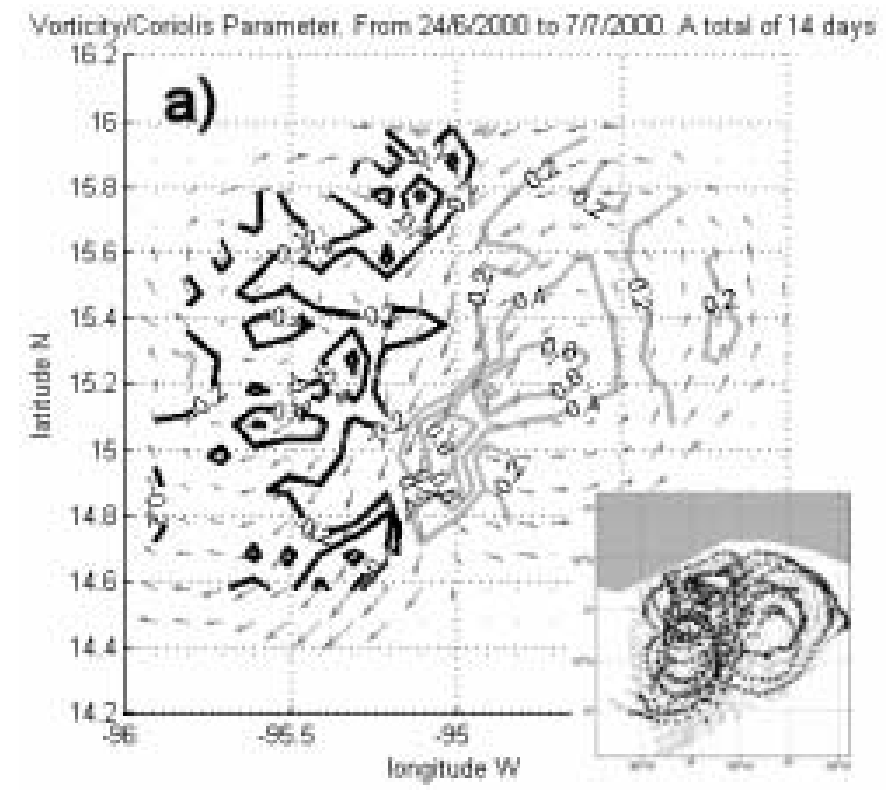

VorticityjConidis Parameter Fmm 22/7/2000 to LQ/2000 A tatal of 14 dyys

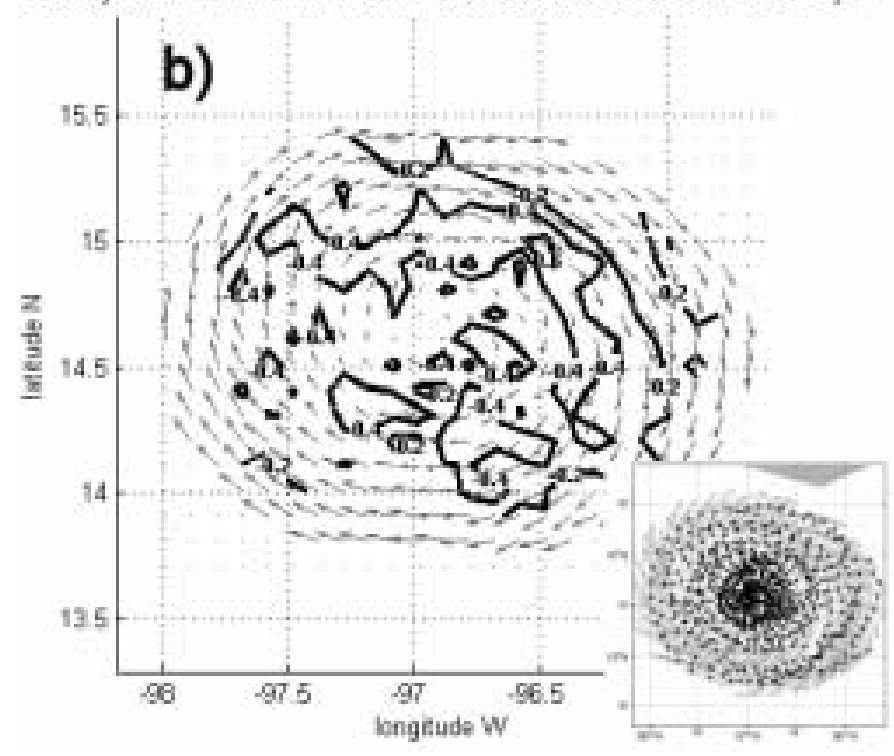



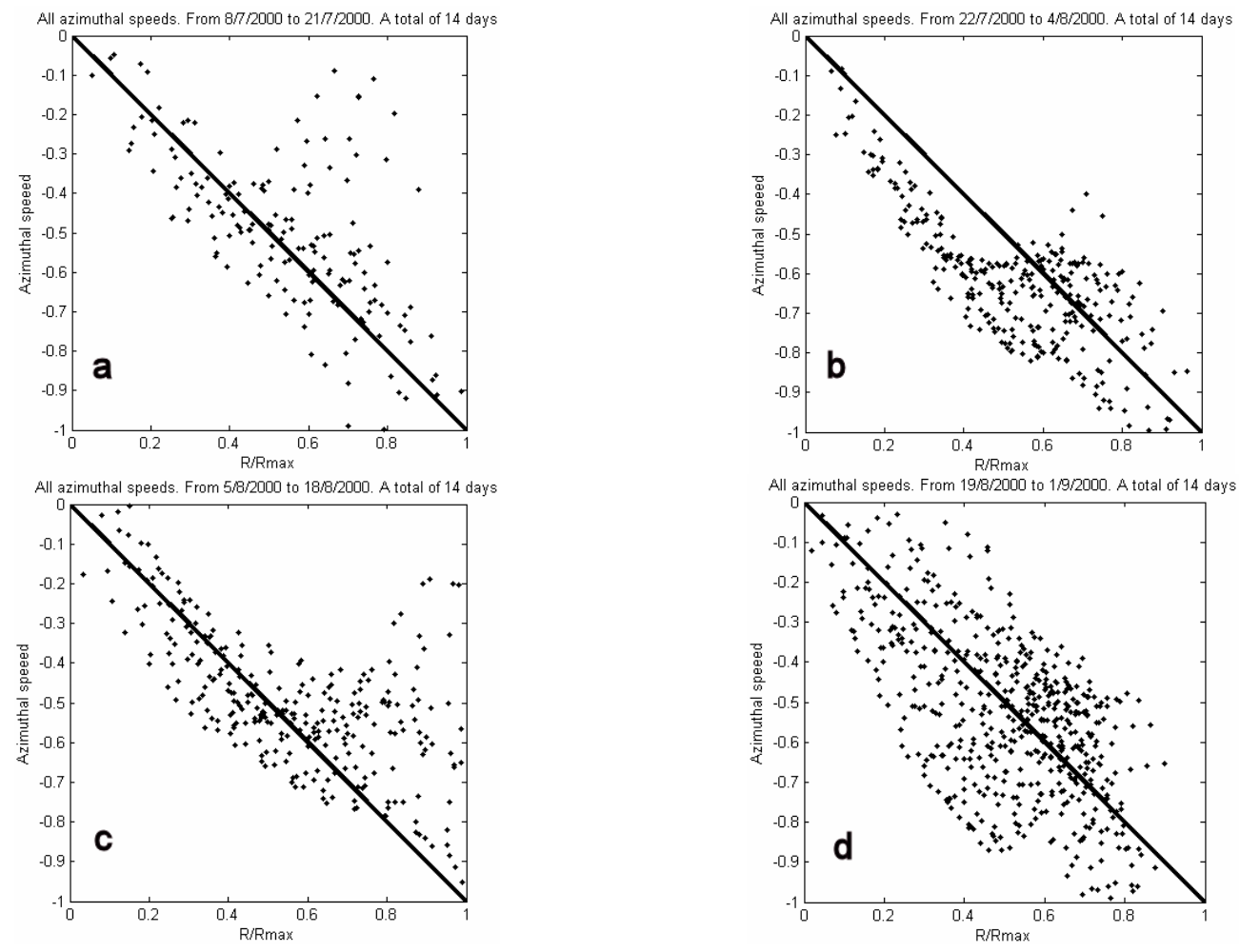
2000 Jun 28 00:00:00.00 (18441)
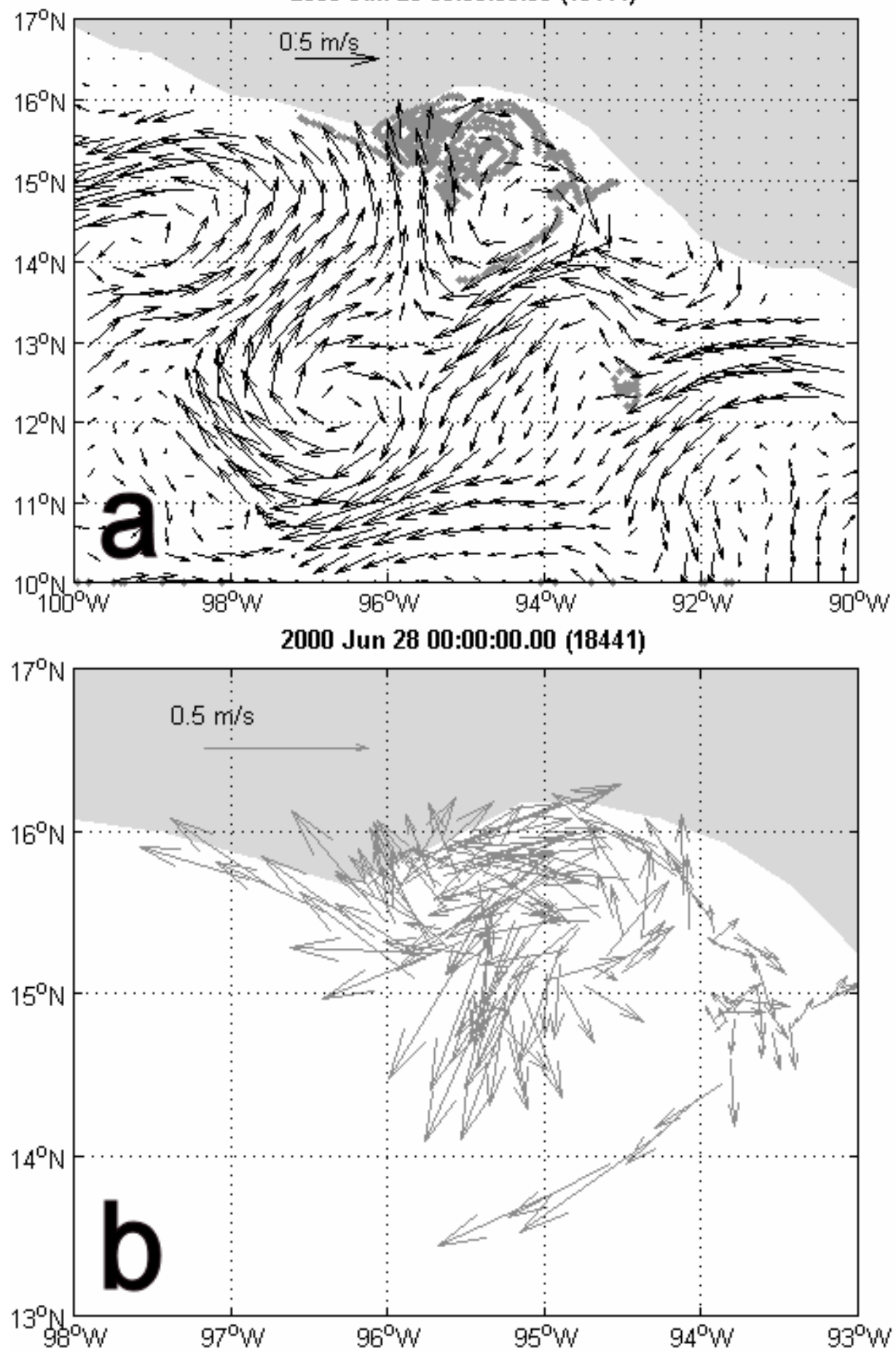

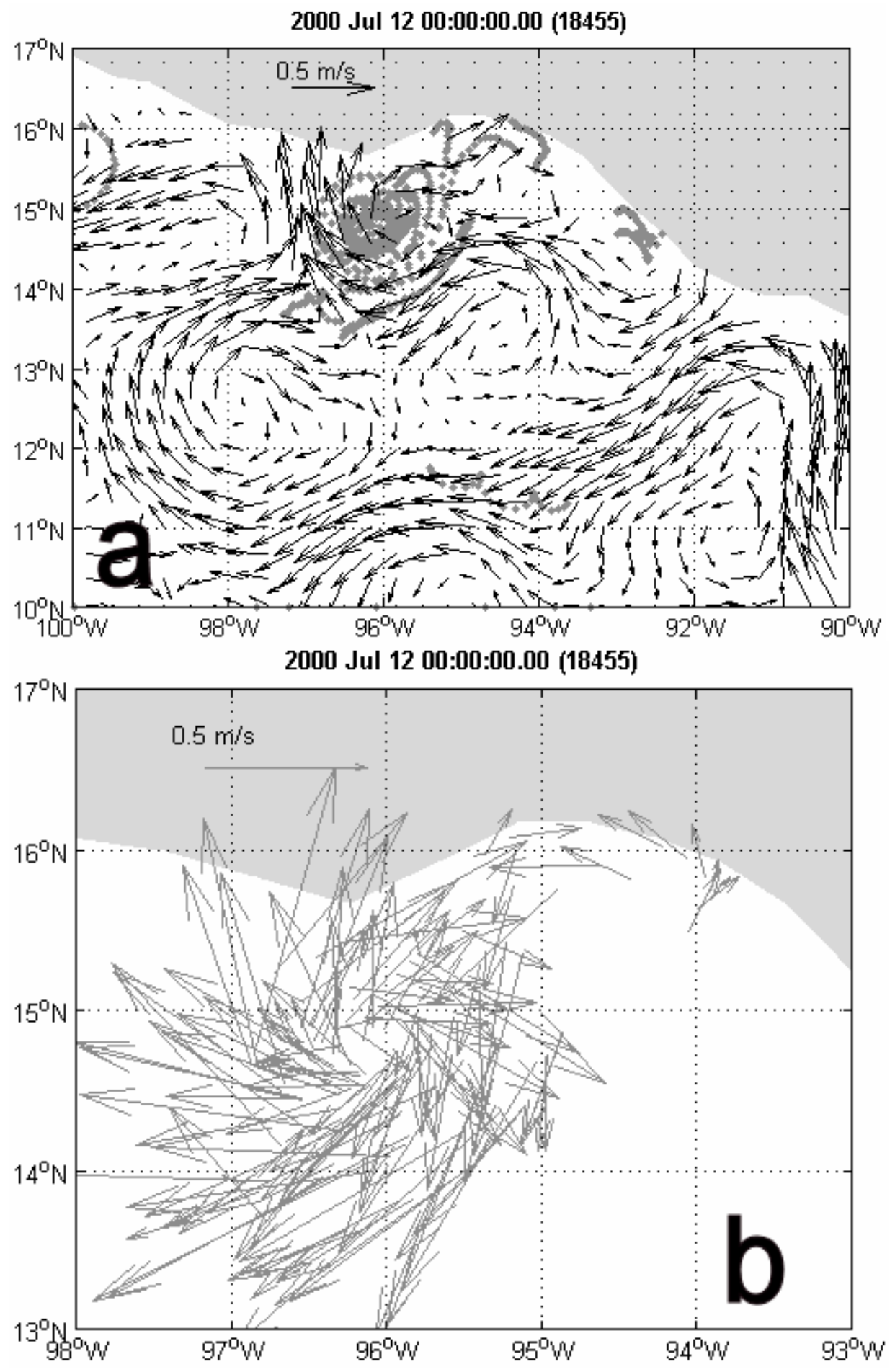

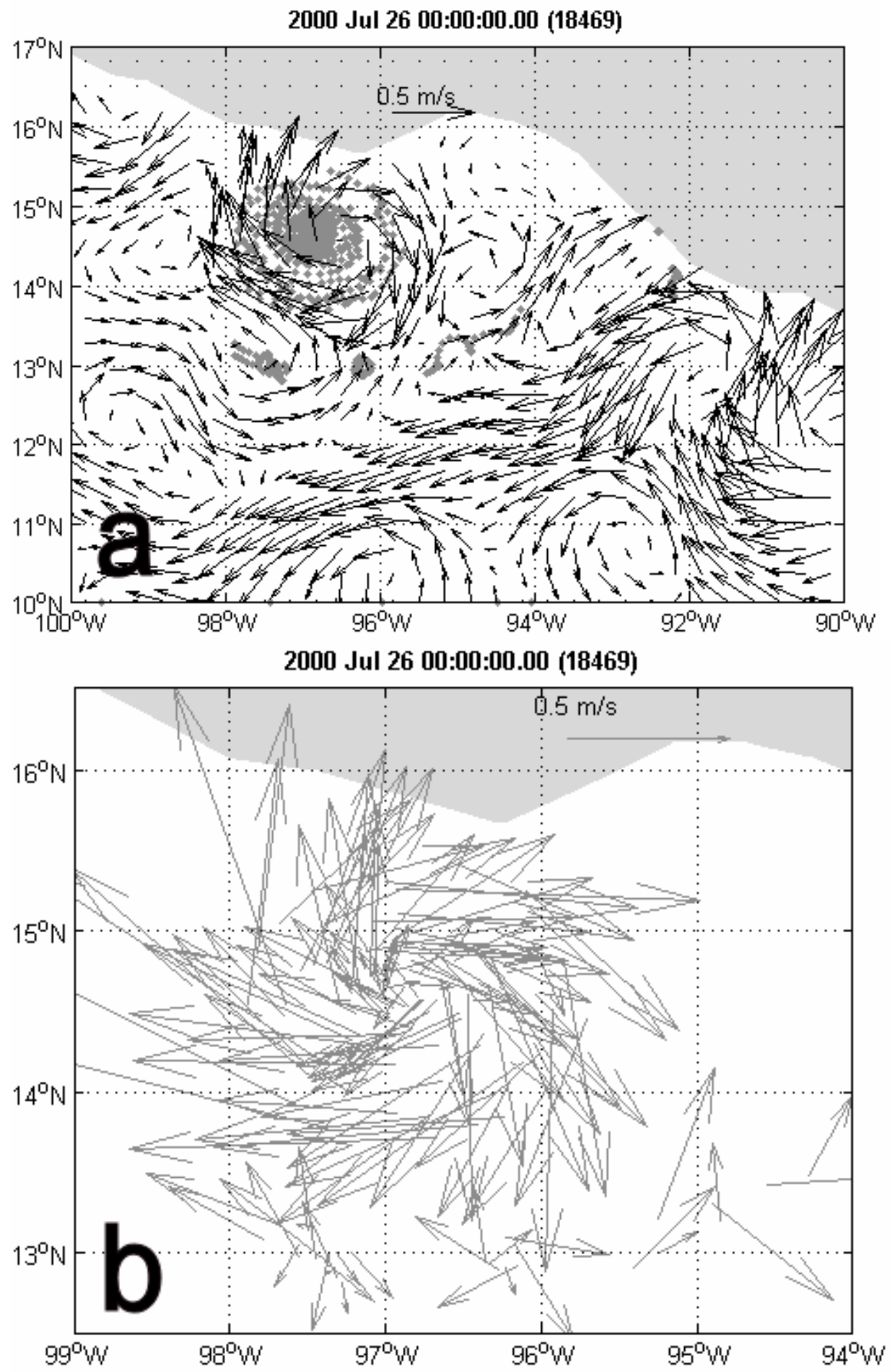

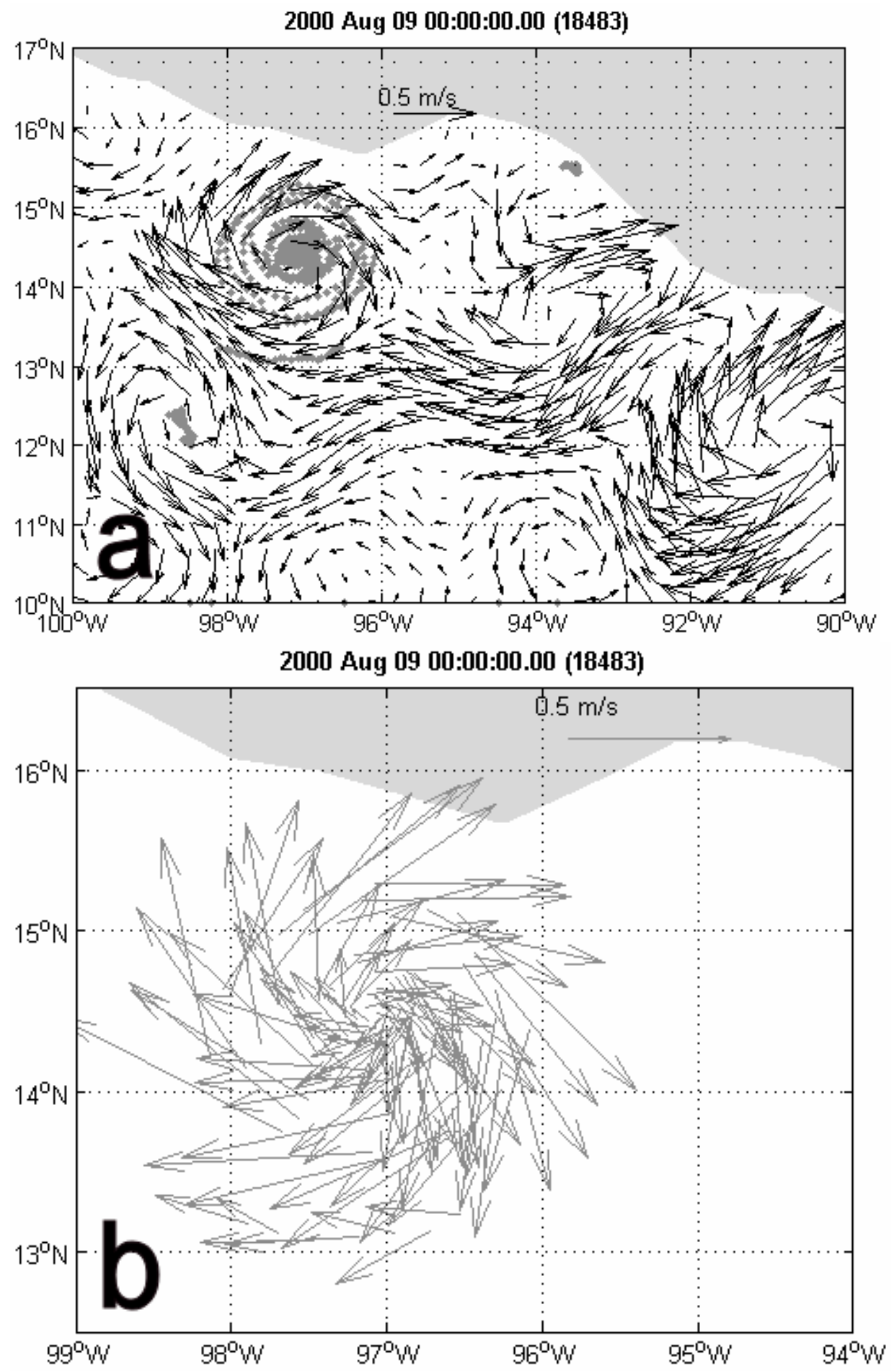

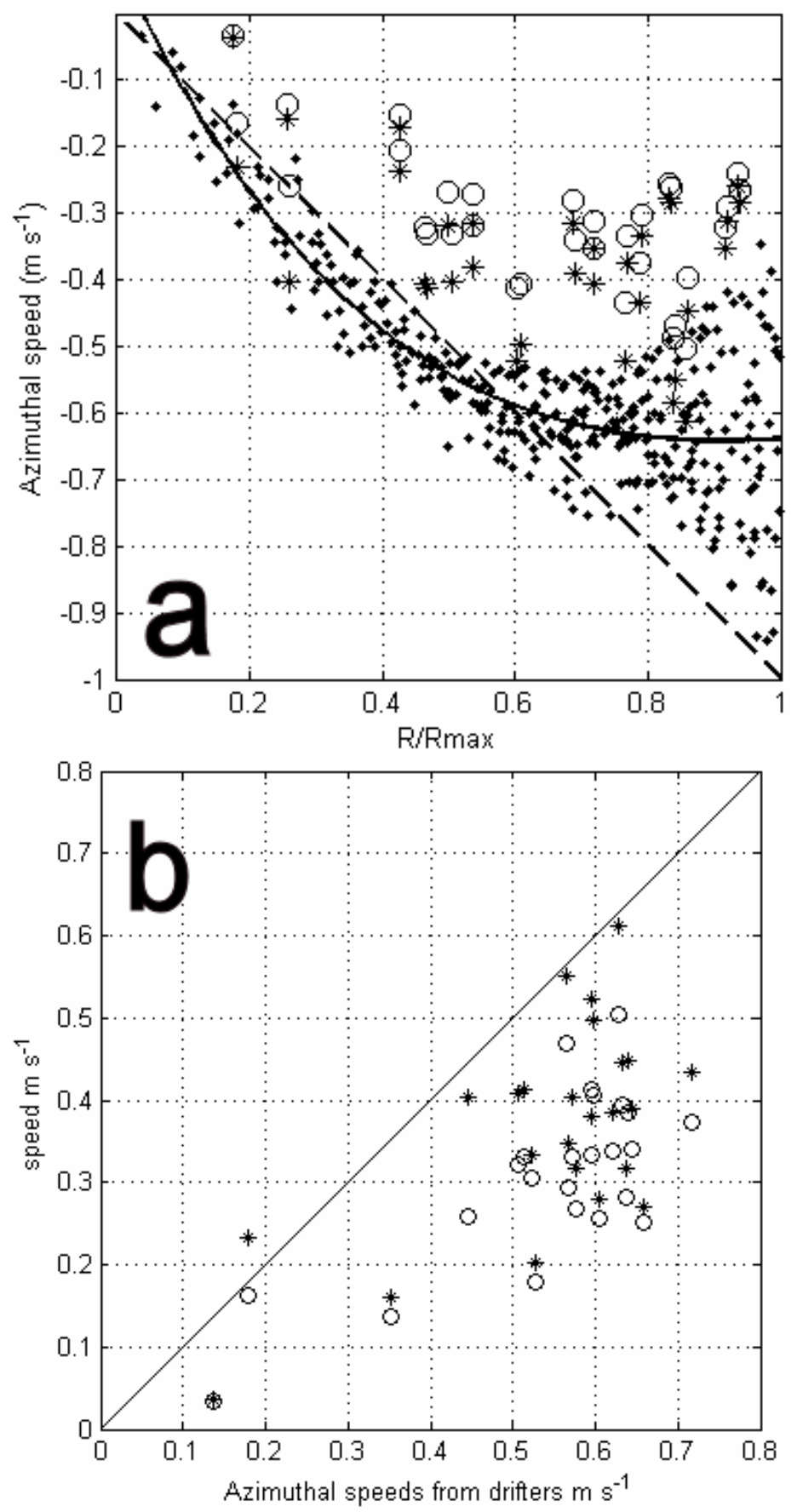

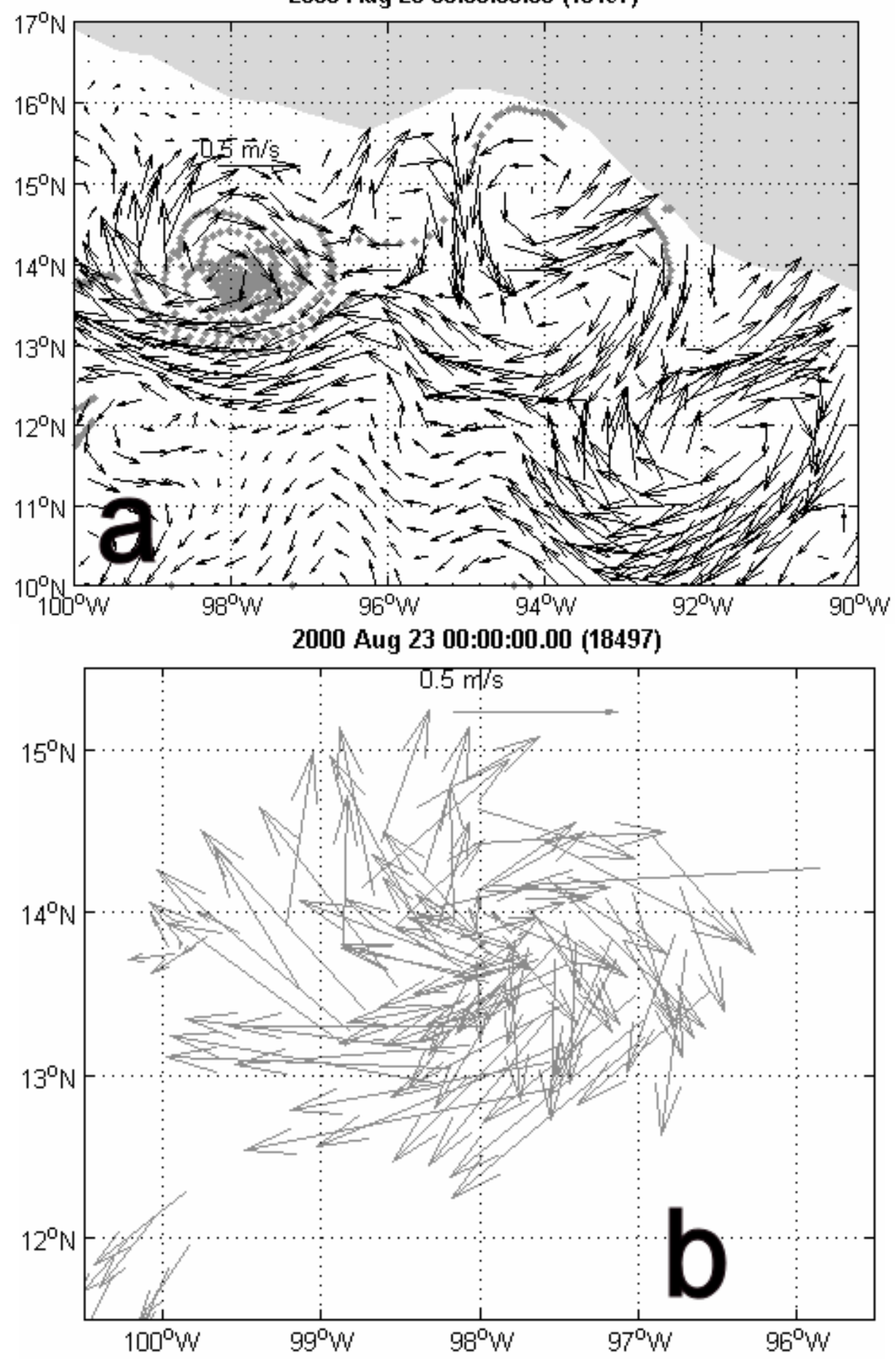
Figure 13
Click here to download Figure: Figure13.doc
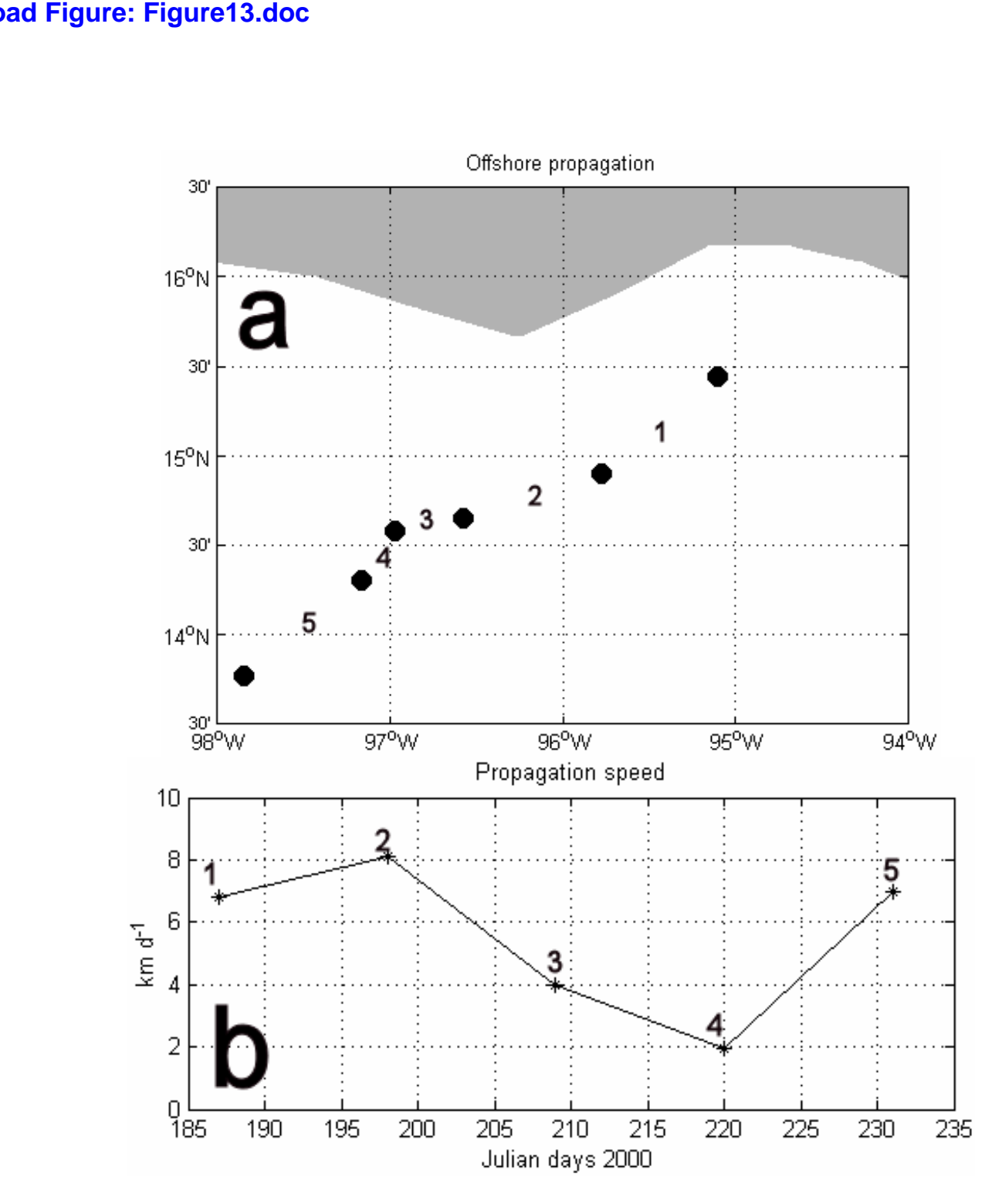